\title{
PERBANDINGAN MEDIA AUDIO VISUAL DAN MEDIA BERBASIS PRAKTIKUUM PADA PROSES PEMBENTUKAN URIN TERHADAP HASIL BELAJAR SISWA KELAS VIII SMP NEGERI 6 KABUPATEN SORONG
}

\author{
FERAWATI HENDI ${ }^{(1)}$ SIROJJUDDIN $^{(1)}$ MIVTHA CITRANINGRUM $^{(1)}$ \\ ${ }^{(1)}$ Program Studi Pendidikan Biologi STKIP Muhammadiyah Sorong \\ E_mail: Ferawati_hendi@yahoo.com
}

\begin{abstract}
ABSTRAK
Penelitian ini bertujuan untuk mengetahui perbandingan media audio visual dan media berbasis praktikum pada proses pembentukan urin terhadap hasil belajar siswa kelas VIII SMP Negeri 6 kabupaten sorong. Penelitian ini dilaksanakan di SMP Negeri 6 kabupaten sorong pada bulan mei 2015. Metode penelitiian yang digunakan adalah quasy experimental. Dengan Desain menggunakan Nonequivalent Control Group Design. Instrumen yang digunakan adalah tes, yang sebelumnya diuji validitas dan uji reabilitas. Hasil uji validitas pada instrument yang digunakan valid. Analisis data berdistribusi homogen dan tidak semuanya berdistribusi normal. Hasil uji t Independent sample test yakni $t_{\text {hitung }}>\mathrm{t}_{\text {tabel }}(3.306<1.68195)$ sehingga dapat disimpulkan bahwa hipotesis nol dan hipotesis alternatif diterima dengan taraf signifikan 95\%. Hasil penelitian dari kelompok kontrol dan kelompok eksperimen diperoleh dari uji hipotesis Ha diterima dan Ho ditolak artinya Terdapat Perbandingan antara media audio visual dan media berbasis praktikum pada proses pembentukan urin terhadap hasil belajar siswa. Adapun hasil yang didapat dari hipotesis tersebut adalah nilai rata-rata hasil belajar siswa kelompok eksperimen lebih besar dari nilai rata-rata hasil belajar kelompok kontrol.
\end{abstract}

Kata Kunci : Media Pembelajaran, Hasil belajar, IPA.

\begin{abstract}
This study aimed to compare the audio-visual media and media based practicum in the process of formation of urine on learning outcomes graders in class VIII SMP country 6 sliding districts. This study in SMP N 6 districts sorong was conducted on 20 May 2015. The research method used was experimental quasy. With design using nonequivalent control group. Instruments used are tests, which previously tested the validity and reability test. The validity of the test results on the instrument used valid. Homogeneous distribution data analysis and not everything normal distribution. Independent sample $t$-test namely the test $t_{\text {hitung }}>t_{\text {tabel }}(3.306<1.68195)$ so it can be concluded that the null hypothesis and the alternative hypothesis isaccepted by a significant level $95 \%$. The results of the control group and the group obtained from testing the hypothesis eksperiment Ha be accepted Ho rejected meaning that there is a comparison between the audio-visual media and media based practicum in the process of formation of urine on student learning outcomes. As for the results obtained from the hypothesis is the average value of student learning outcomes experimental group is greater than the average value of learning outcomes of the control group.
\end{abstract}

Keywords : Instructional media, learning outcomes, IPA.

\section{PENDAHULUAN}

Pendidikan merupakan salah satu upaya untuk meningkatkan sumber daya manusia. Pendidikan juga merupakan suatu kebutuhan pokok bagi setiap individu yang ingin maju, baik itu anak yang normal maupun anak yang mengalami kelainan fisik dan atau mental. Dalam UU No. 20 tahun 2003 Tentang Sistem Pendidikan Nasional dikatakan bahwa pendidikan adalah usaha sadar dan terencana untuk mewujudkan suasana belajar dan proses pembelajaran agar peserta didik secara aktif mengembangkan potensi dirinya untuk memiliki kekuatan spiritual keagamaan, pengendalian diri, kepribadian, kecerdasan, akhlak mulia, serta keterampilan yang diperlukan dirinya dalam masyarakat, bangsa dan Negara ${ }^{(1)}$

Biologi sebagai salah satu bidang IPA menyediakan berbagai pengalaman belajar untuk memahami konsep dan proses sains, sehingga siswa perlu dibantu untuk mengembangkan keterampilan proses supaya mereka mampu menjelajahi dan memahami alam sekitar (BSNP, 2006). Untuk dapat mengembangkan keterampilan proses siswa, dibutuhkan cara pembelajaran yang mengutamakan kepada aktivitas belajar siswa, karena pada prinsipnya belajar adalah berbuat. Tanpa aktivitas, proses belajar tidak mungkin berlangsung dengan baik ${ }^{(2)}$

$$
\text { proses belajar adalah dalam rangka }
$$
mempengaruhi siswa agar dapat menyesuaikan diri sendiri maupun dengan lingkungannya, supaya menimbulkan perubahan dalam dirinya yang memungkinkan berfungsi dalam kehidupan masyarakat. Salah satu cara yang digunakan untuk dapat membuat proses belajar menarik dengan menggunakan segala sesuatu untuk menyalurkan materi dari guru ke siswa, sehingga dapat merangsang pikiran, perasaan dan minat serta perhatian siswa terhadap pembelajaran yang disebut media pembelajaran (Sadikman dkk,1996).

Untuk memberikan rangsangan dan stimulus yang kuat bagi siswa untuk terus belajar, sehingga 
suasana belajar menjadi lebih aktif bentuk pengembangan dalam penyampaian materi/bahan ajar melalui media audio visual dan media berbasis praktikum dapat memungkinkan siswa melakukan eksplorasi lebih dalam. Disamping itu dengan adanya media audio visual dan media berbasis praktikum memungkinkan efisiensi pembelajaran juga dapat di tingkatkan ${ }^{(3)}$

\section{METODE PENELITIAN}

Jenis penelitian yang digunakan adalah quasy experimental. Dengan Desain menggunakan Nonequivalent Control Group Design. ini di ukur dan di observasi pada waktu sebelum dan sesudah perlakuan. Hanya pada desain ini kelompok eksperimen maupun kelompok kontrol tidak dipilih secara random $^{(4)}$

Adapun gambar diagram desain ini adalah:

\begin{tabular}{|c|}
\hline $\mathrm{O}_{1} \times \mathrm{X}_{2}$ \\
\hline $\mathrm{O}_{3} \mathrm{XO}_{4}$ \\
\hline
\end{tabular}

Populasi dalam penelitian ini adalah seluruh peserta didik kelas VIII SMP N 6 KABUPATEN SORONG.

Sampel dalam penelitian adalah siswa kelas VIII yang terdiri dari dua kelas. Kelas VIIIA sebagai kelas kontrol dan kelas VIII B sebagai kelas eksperimen sebagai kelas uji coba instrumen yang sudah menerima materi tersebut.

Jenis instrumen yang digunakan dalam penelitian eksperimen disini berupa observasi, Tes, dan dokumentasi.

\section{PEMBAHASAN}

Penelitian ini dilaksanakan di SMP Negeri 6 Kabupaten Sorong dengan mengambil dua kelas untuk dijadikan sebagai sampel penelitian yaitu kelas VIII A sebagai kelas kontrol dan kelas VIII B sebagai kelas eksperiman. Sebelum kedua kelas tersebut diberikan perlakuan, terlebih dahulu diberikan pretest ( soal proses pembentukan urin). Hal ini dimaksudkan untuk melihat kondisi awal kedua sampel yang diambil memiliki sifat homogen atau tidak. Setelah itu, kedua kelas tersebut diberikan perlakuan yang berbeda selam proses pembelajaran IPA. Kemudian pada akhir penelitian kedua kelas tersebut diberikan posttest (soal proses pembentukan urin), data skor pretest dan posttest berjumlah dari 44 siswa yang terdiri dari kelompok kontrol sebanyak 22 siswa dan kelompok eksperimen sebanyak 22 siswa.

Tes hasil belajar yang diberikan kepada 22 siswa dari kelompok kontrol yang diberlakukan di SMP Negeri 6 Kabupaten Sorong dilaksanakan pada tanggal 20 Mei 2015 untuk mengetahui perbandingan dalam sebuah penelitian. Hasil tes awal dan akhir pada kelompok kontrol sebelum dan sesudah menggunakan media Audio Visual. Adapun dapat dilihat pada table berikut:

Rangkuman Skor Rata-Rata Kelompok Kontrol

\begin{tabular}{|c|c|}
\hline Statistika Deskriptif & Perolehan Skor \\
\hline Jumlah Siswa (N) & 22 \\
\hline
\end{tabular}

\begin{tabular}{|c|c|}
\hline Minimum (Xmin) & 45 \\
\hline Maksimum $($ Xmax $)$ & 75 \\
\hline Mean $\left(x^{-}\right)$ & 58.18 \\
\hline Simpangan Baku (S) & 7.645 \\
\hline
\end{tabular}

Tabel diatas menunjukan bahwa dikelas kontrol terdiri dari 22 siswa diperoleh nilai tertinggi yaitu 75 dan nilai terendah 45 . Dengan kemampuan rata-rata seluruh siswa adalah 58.18. dari nilai simpangan baku yang diperoleh yaitu sebesar 7.645 menunjukan bahwa rentang nilai yang sebenarnya yang diperoleh dikelas kontrol berkisar antara nilai $50.535(58.18$ - 7.645) sampai $65.825(58.18+7.645)$.

Tes hasil belajar yang diberikan kepada 21 siswa dari kelompok eksperimen yang diberlakukan di SMP Negeri 6 Kabupaten Sorong dilaksanakan pada tanggal 21 Mei 2015 untuk mengetahui perbandingan dalam sebuah penelitian. Hasil tes awal dan akhir pada kelompok eksperimen sebelum dan sesudah menggunakan media Berbasis Praktikum pada proses pembentukan urin. Adapun dapat dilihat tabelnya sebagai berikut:

Rangkuman Skor Rata-Rata Kelompok Eksperimen

\begin{tabular}{|c|c|}
\hline Statistika Deskriptif & $\begin{array}{c}\text { Perolehan } \\
\text { Skor }\end{array}$ \\
\hline Jumlah Siswa (N) & 22 \\
\hline Minimum (Xmin) & 55 \\
\hline Maksimum $($ Xmax $)$ & 80 \\
\hline Mean $\left(x^{-}\right)$ & 66.14 \\
\hline Simpangan Baku (S) & 8.300 \\
\hline
\end{tabular}

Tabel diatas menunjukan bahwa dikelas Eksperimen terdiri dari 22 siswa diperoleh nilai tertinggi yaitu 80 dan nilai terendah 55. Dengan kemampuan rata-rata seluruh siswa adalah 66.14. dari nilai simpangan baku yang diperoleh yaitu sebesar 8.300, menunjukan bahwa rentang nilai yang sebenarnya yang diperoleh dikelas kontrol berkisar antara nilai $57.84(66.14$ - 8.300) sampai 8366.14 $(66.14+8.300)$.

Analisis hasil penelitian meliputi beberapa uji, uji yang dimaksud dalam penelitian ini yaitu uji prasyarat dan uji hipotesis. Uji prasyarat meliputi uji validitas, uji reabilitas, uji homogenitas dan uji reabilitas. Uji hipotesis meliputi uji T 2 sampel bebas. Pengolahan data hasil penelitian menggunakan aplikasi SPSS 20.

Hasil uji prasyarat dengan menggunakan uji homogenitas dan uji normalitas data yang dijadikan sebagai patokan mengambil keputusan untuk uji hipotesis. Uji homogenitas dari kelompok kontrol dan kelompok eksperimen mempunyai varian yang sama atau homogen dan Untuk uji normalitas dari kelompok kontrol berdistribusi normal dan kelompok eksperimen besdistribusi tidak normal, maka uji hipotesisnya menggunakan uji t.

Berdasarkan hasil penelitian yang diperoleh, terlihat adanya perbandingan nilai rata - rata menggunakan media audio visual pada kelompok kontrol dan nilai rata-rata menggunakan media 
berbasis praktikum pada kelompok eksperimen. Adapun dapat dilihat pada table dibawah ini :

\section{Perbandingan nilai rata-rata kelompok kontrol dan kelompok eksperimen.}

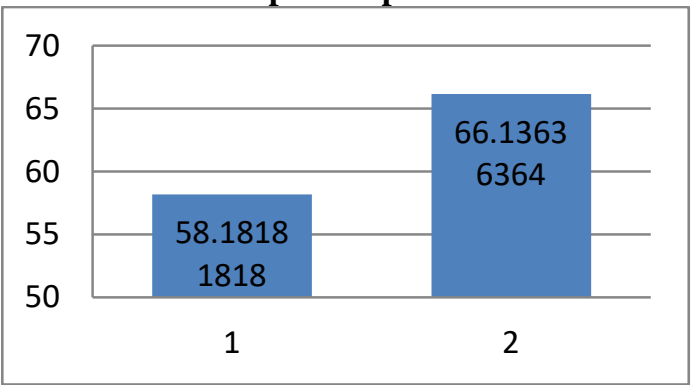

Pada table diatas, Rata - rata nilai media audio visual pada kelompok kontrol didapat sebesar 58.18 dan rata - rata media berbasis praktikum pada kelompok eksperimen didapat sebesar 66.14 dan setelah dilakukan perhitungan hipotesis dengan menggunakan uji $\mathrm{t}$ pada taraf signifikan $\alpha=0.05$ diperoleh $t_{\text {hitung }}>t_{\text {tabel }}$ atau $3.306>1.68195$, yang berarti terdapat perbandingan yang signifikan antara siswa yang diberi perlakuan dengan menggunakan media audio visual pada kelompok control dan siswa yang diberi perlakuan dengan menggunakan media berbasis praktikum pada kelompok eksperimen pada proses pembentukan urin terhadap hasil belajar siswa. Dengan demikian diperoleh dari uji hipotesis $\mathrm{Ha}$ diterima dan Ho ditolak artinya terdapat perbandingan antara media audio visual dan media berbasis praktikum pada proses pembentukan urin terhadap hasil belajar siswa. Adapun hasil yang didapat dari hipotesisnya adalah nilai rata-rata hasil belajar siswa pada kelompok eksperimen yang menggunakan media berbasis praktikum lebih besar dari nilai rata - rata hasil belajara siswa kelompok kontrol yang menggunakan media audio visual.

\section{KESIMPULAN}

Berdasarkan hasil penelitian dan analisis data, maka dapat disimpulkan bahwa media audio visual dan media berbasis praktikum pada proses pembentukan urin terhadap hasil belajar siswa SMP Negeri 6 Kabupaten Sorong terdapat perbandingan dari kedua media tersebut. Dimana nilai rata-rata hasil belajar siswa kelompok eksperimen yang menggunakan media berbasis praktikum lebih besar dari kelompok kontrol yang menggunakan media audio vidual.

dalam upaya meningkatkan hasil belajar siswa merupakan hasil dari proses pembelajaran yang di alami oleh siswa. Siswa akan menghasilkan perubahan-perubahan di bidang pengetahuan, keterampilan juga dalam bentuk nilai dan sikap. Oleh karena itu prestasi belajar yang tinggi dapat meningkatkan pengetahuan/pemahaman, keterampilan, juga nilai dan sikap, sehingga dapat menjadi bekal siswa dalam menghadapi perkembangan teknologi informasi dan komunikasi yang semakin pesat.

Strategi belajar dengan menggunakan media berbasis praktikum dapat mendorong siswa untuk mengembangkan keterampilan dan kemampuan berpikir dalam proses belajar mengajar sehingga dapat dijadikan sebagai salah satu alternatif untuk meningkatkan mutu pembelajaran.

\section{DAFTAR PUSTAKA}

${ }^{(1)}$ UU No.22 tahun 2003 tentang Sistem Pendidikan Nasional.

${ }^{(2)}$ BSNP. 2006. Standar Isi untuk Satuan Pendidikan Dasar dan Menengah. Jakarta: Departemen Pendidikan Nasional.

${ }^{(3)}$ Hamalik, Oemar. 2001. Metode Belajar dan Kesulitan Belajar. Bandung: Tarsito.

${ }^{(4)}$ Sugiyono (2014) Metode Penelitian Kombinasi (Mixed Methods). Bandung. CV Alfabeta. 